\title{
Brightness discrimination loss after lesions of the corpus striatum in the white rat*
}

\author{
ROBERT THOMPSON, HOLLY CHETTA, and JOSEPH E. LEDOUX \\ Louisiana State University, Baton Rouge, Louisiana 70803
}

\begin{abstract}
Multiple bilateral electrolytic lesions destroying the posterior regions of the corpus striatum (including the globus pallidus) in the rat produced a marked deficit in retention of a brightness discrimination habit. Lesions placed more anteriorly within the corpus striatum had little effect. No effect on retention followed bilateral lesions of either the nucleus accumbens septi, infralimbic area, or frontal cortex. It would appear that the posterior division of the corpus striatum must be included within the "general memory system" (along with the brainstem reticular formation) by virtue of its contribution to the expression of a wide variety of learned responses.
\end{abstract}

An ensemble of nervous structures of the rat brain has recently been identified by the lesion method to be involved in the expression (memory) of a wide variety of learned responses, including visual and kinesthetic discrimination habits, conditioned avoidance responses, a maze habit, and latch box problems (see Thompson \& Thorne, 1973). This ensemble, which has been termed the "general memory system," embraces the ventral portions of the brainstem reticular formation and its associated nuclei (red nucleus, substantia nigra, interpedunculo-central tegmental area, subthalamus, lateral hypothalamus, and posterior thalamus). Thompson and Thorne did not include the corpus striatum within the general memory system because of a discrepancy within the literature related to retention of a brightness discrimination in the presence of lesions to this subcortical mass (see Thompson, 1969, vs Thompson \& Massopust, 1960). On the other hand, there seems to be little doubt that lesions of the corpus striatum impair retention of a kinesthetic discrimination habit (Thompson, Malin, \& Hawkins, 1961), a conditioned avoidance response (Mitcham \& Thomas, 1972), a maze habit (Thompson, 1974), and latch box problems (Spiliotis \& Thompson, 1973).

The purpose of the present study was to determine whether or not extensive bilateral lesions of the corpus striatum would interfere with retention of a brightness discrimination habit. Lesions of anatomically related structures (frontal cortex, infralimbic area, and nucleus accumbens septi) were also investigated.

\section{METHOD}

Adult male albino rats of the Wistar strain were trained to approach a white stimulus card and avoid an adjacent black stimulus card in a Thompson-Bryant (1955) discrimination box. Under the motive of escape (or avoidance) of footshock, a response to the unlocked white card admitted $\mathrm{S}$ to the goalbox, whereas a response to the locked black card was automatically punished by mild footshock. Eight trials were given daily with an

*This research was supported in part by a grant from the Graduate Council of Research, Louisiana State University. intertrial interval of $60 \mathrm{sec}$. The criterion of learning consisted of no more than one error in 2 successive days.

Following learning, one group (Group CS) sustained bilateral electrolytic lesions of the corpus striatum. The size and locus of the lesions were intentionally varied in order to investigate the possible existence of a "mass action" effect as well as a "critical striatal focus." In most cases, lesions were produced in two stages with an interoperative period of 7-10 days. A second group (Group ILA) sustained one-stage bilateral electrolytic lesions of the infralimbic area, and a third group (Group NAS) received one-stage bilateral electrolytic lesions of the nucleus accumbens septi. The fourth group (Group FC) was subjected to one-stage bilateral aspiration of the frontal cortex, and the last group (Group NC) served as normal controls.

After a recovery (or rest) period of 2-3 weeks, all $\mathrm{ss}$ were given a retention test which consisted of relearning the brightness discrimination habit. Retention was measured in terms of percentage error savings scores using the conventional formula.

Following the retention test, histological verification of the locus and extent of the lesions was carried out. Details of the surgical and histological procedures have been reported elsewhere (Thompson, 1971).

\section{RESULTS}

A total of 10 Ss composed Group CS. Six suffered lesions at caudal levels which damaged portions of the caudoputamen complex as well as the globus pallidus (Fig. 1A). The remaining four had lesions at rostral levels which spared the pallidum (Fig. 1B). The two Ss of Group NAS sustained extensive damage to the nucleus accumbens septi and the underlying ventral olfactory cortex (Fig. 1C). The three Ss of Group ILA sustained lesions of the infralimbic area extending from the frontal poles to the septal nuclei. The four Ss of Group FC received frontal cortical lesions which, in all cases, included the frontal poles and the major portion of what Krieg (1946) has designated as Area 10. The average extent of neocortical damage was $17.8 \%$ with a range of $15 \%-22 \%$.

As shown in Table 1, only Group CS exhibited relatively poor savings scores on the brightness discrimination habit. After finding a significant $\mathrm{H}$ with the use of the Kruskal-Wallis one-way analysis of 


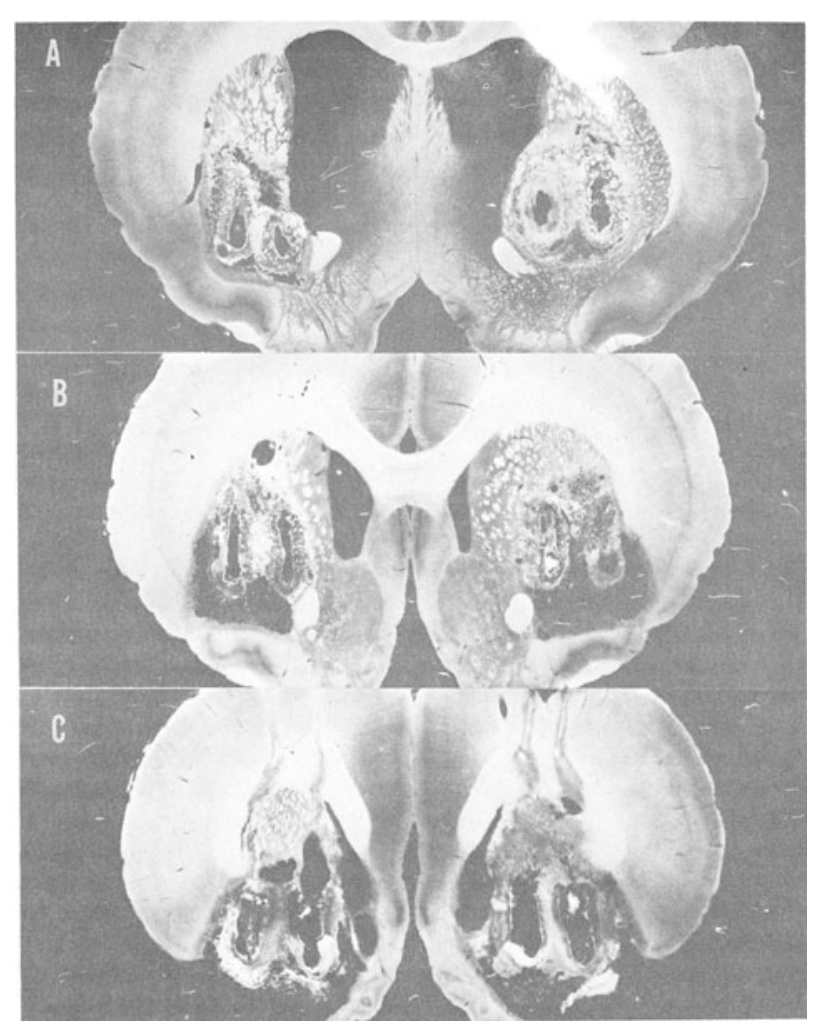

Fig. 1. Photographs of unstained sections showing lesions of the posterior corpus striatum (A) in one rat (savings $=-25 \%$ ), anterior corpus striatum (B) in one rat (savings $=100 \%$ ), and nucleus accumbens septi $(C)$ in one rat (savings $=82 \%$ ).

variance, specific group comparisons disclosed that Group CS was significantly inferior to each of the other four groups in retention scores (ps $<.05$ as computed by the Mann-Whitney test). All other group comparisons fell considerably short of statistical significance.

Evidence suggesting the possible existence of a critical striatal focus for brightness discrimination deficits comes from a comparison between the Ss with posterior damage (which involved the globus pallidus) and the Ss with anterior damage (which involved the caudoputamen rostral to the pallidum). The former earned a mean savings score of $13.8 \%$, whereas the latter earned a mean savings score of $80.0 \%$-this difference between the subgroups was significant at the .01 level. It must be emphasized, however, that the Ss with anterior lesions

Table 1

Learning and Retention Scores for All Groups

\begin{tabular}{lrrrrrr}
\hline & & \multicolumn{2}{c}{ Learning Errors } & & \multicolumn{2}{c}{$\begin{array}{c}\text { Percent } \\
\text { Error Savings }\end{array}$} \\
\cline { 7 - 8 } \cline { 6 - 7 } Group & N & Mean & Range & & Mean & Range \\
\hline NC & 6 & 11.5 & $6-18$ & & 90.5 & $43-100$ \\
CS & 10 & 10.8 & $5-21$ & & 46.3 & $-25-100$ \\
ILA & 3 & 13.3 & $10-15$ & & 95.0 & $85-100$ \\
NAS & 2 & 14.5 & $11-18$ & & 91.0 & $82-100$ \\
FC & 4 & 10.5 & $8-14$ & & 84.8 & $67-100$ \\
\hline
\end{tabular}

tended to suffer less damage to the corpus striatum than those having posterior lesions. Since the rank-order correlation between size of the lesion and loss in retention for all $10 \mathrm{Ss}$ of Group CS was found to be significant $($ rho $=.57)$, the differential effect of anterior vs posterior lesions must be interpreted with caution.

The general behavior of the Ss with posterior lesions also differed remarkably from that of the Ss with anterior lesions. The former showed transient aphagic-adipsic disorders, exhibited little to no exploratory activity on the surface of an observation table, required frequent footshocks to force an escape response, and had difficulty pushing aside the white card in order to enter the goalbox. The latter, in contrast, showed no aphagic-adipsic disorders, exhibited hyperexploratory activity, and behaved normally in the test situation. It is of interest to note that the general behavior of the Ss with frontal cortical lesions was similar to that displayed by the Ss with posterior striatal lesions. The only behavioral disturbances noted in the Ss composing Groups NAS and ILA included a defective escape response and difficulty in displacing the white card.

\section{DISCUSSION}

These results confirm earlier findings (Thompson, 1969) in showing that extensive lesions of the corpus striatum markedly impair retention of a brightness discrimination habit in the rat. The absence of any deleterious effect noted in the Thompson and Massopust (1960) study is, in all probability, due both to the diminutive size of the lesions and to the placement of the lesions within the anterior parts of the striatum. In any case, it is clear that the corpus striatum and, in particular, the globus pallidus must be included within the general memory system by virtue of its apparent contribution to the expression of a wide variety of learned responses in the rat.

Interpretation of the generalized amnestic effects following lesions of the corpus striatum (or any other part of the general memory system) is complicated by the fact that such lesions are often associated with an assortment of disturbances in so-called species-typical behavior, including eating, drinking, pain-escape, exploration, and the like (see Thompson, 1974). In fact, the anatomical boundaries of the general memory system correspond closely to those demarcating the "reptilian brain" which, according to MacLean (1970), mediates genetically endowed behavior patterns. This correspondence raises many interesting questions, including the possibility that those brain regions concerned with the expression of unlearned behaviors may also be the ones that are concerned with the expression of acquired behaviors.

\section{REFERENCES}

Krieg, W. J. S. Connections of the cerebral cortex: I. The albino rat: A. Topography of the cortical areas. Journal of Comparative Neurology, 1946, 84, 221-275.

Maclean, P. D. The triune brain, emotion, and scientific bias. In F. O. Schmitt (Ed.), The neurosciences. New York: Rockef ellar University Press, 1970.

Mitcham, J. C., \& Thomas, R. K. Effects of substantia nigra and caudate nucleus lesions on avoidance learning in rats. Journal of Comparative \& Physiological Psychology, 1972, 81, 101-107.

Spiliotis, P. H., \& Thompson, R. The "manipulative response memory system" in the white rat. Physiological Psychology, 1973, 1, 101-114. 
Thompson, R. Localization of the "visual memory system" in the white rat. Journal of Comparative \& Physiological Psychology, 1969, 69, 1-29.

Thompson, R. Introducing subcortical lesions by electrolytic methods. In R. D. Myers (Ed.), Methods in psychobiology. New York: Academic Press, 1971.

Thompson, R. Localization of the "maze memory system" in the white rat. Physiological Psychology, 1974, in press.

Thompson, R., \& Bryant, J. H. Memory as affected by activity of the relevant receptor. Psychological Reports, 1955, 1, 393-400.

Thompson, R., Malin, C. F., \& Hawkins, W. F. Effect of subcortical lesions on retention of a kinesthetic discrimination habit. Experimental Neurology, 1961, 3, 367-374.

Thompson, R. \& Massopust, L. C. The effect of subcortical lesions on retention of a brightness discrimination in rats. Journal of Comparative \& Physiological Psychology, 1960, 53, 488-496.

Thompson, R., \& Thorne, B. M. Brainstem reticular formation lesions: Amnestic effects on learned habits in the rat. Physiological Psychology, 1973, 1, 61-70.

(Received for publication January 28, 1974.)

Bulletin of the Psychonomic Society

1974, Vol. 3 (4), 295-297

\title{
Effects of stimulus duration on temporal facilitation*
}

\author{
HALSEY H. MATTESON, JOEL H. LEWIS $\dagger$, and WILLIAM P. DUNLAP \\ Tulane University, New Orleans, Louisiana 70118
}

\begin{abstract}
High-luminance surrounds can reduce perceptual latency (temporal facilitation). Test stimuli of four durations (5 msec, $100 \mathrm{msec}$, 5-sec onset, and 5-sec offset) were judged against comparison stimuli of several durations. Temporal facilitation of almost $100 \mathrm{msec}$ was obtained with the 5-msec test regardless of the comparison used. With $100 \mathrm{msec}$ and 5 -sec onset test stimuli, temporal facilitation was less and occured only with identical test and comparison stimuli. Offset latencies were shorter than onset latencies, and only one $\mathrm{S}$ showed temporal facilitation with offset test stimuli. Results were discussed in terms of the temporal course of brightness.
\end{abstract}

An intense surround can shorten perceptual latency of a stimulus by as much as $100 \mathrm{msec}$, compared to latency on a dark background (temporal facilitation). Using the perceived-order method, Matteson $(1970,1971)$ found temporal facilitation with brief $(5 \mathrm{msec})$ test stimuli. Studies reporting similar latency reduction with the Pulfrich pendulum (references in Matteson, 1971) and the Hess effect (Prestrude \& Baker, 1971) used narrow, rapidly moving lines, which produce brief stimulation of a given retinal area. With longer-duration test stimuli, Bartlett and MacLeod (1954) and Hansteen (1971) found that intense backgrounds increased latency. One

*This research was supported by Grant EY-00021 from the National Eye Institute to the first author.

†Present address: Department of Psychology, Kearney State College, Kearney, Nebraska 68847. possible explanation of this discrepancy is that temporal facilitation might occur only with brief test stimuli.

It has been suggested previously (Matteson, 1971) that temporal facilitation might be due to suppression of visual persistence by light adaptation. Piéron's (1934) hypothetical brightness-vs-time curve reaches an initial peak ("on" firing), levels off to a somewhat lower stable level for the remainder of stimulus duration, and then fades out after stimulus offset (persistence). Contrast data (Heinemann, 1955) show that a surround reduces brightness of weak stimuli more than it reduces brightness of intense stimuli. If contrast results are applied to Piéron's curve, an intense surround should produce the smallest reduction of the initial peak ("on" response), slightly more reduction of the lower brightness after the initial peak, and greatest reduction 